\title{
The Gender Pay Gap in the Platform Economy: Comparing the Importance of Market and Organisational Dynamics on Two German Crowdworking Platforms
}

\section{Anja-Kristin Abendroth}

\begin{abstract}
The rise of the platform economy has brought about crowdwork as a new form of flexible work where individuals solve specific problems or provide specific services or products in exchange for payment via online platforms. Survey data for crowdworkers in Germany collected by the 'Digital Future' collaborative research unit are used to compare gender inequalities in hourly pay among crowdworkers sampled from a marketplace platform and a micro-task platform. The results reveal that fathers earn higher hourly pay than mothers and childless women and men, but only on the marketplace platform. These differences can partly be explained by fathers being better positioned in the overall labour market and fathers' investment patterns in crowdwork, with longer seniority on the platform and quick task performance, which results in higher hourly pay. Investments in crowdwork and overall labour market positioning are only of modest importance on the micro-task platform. This points to different organisational settings and inequality regimes on the two platforms under study.
\end{abstract}

Keywords: platform labour, platform economy, crowdwork, algorithmic control, gender inequalities, gender pay gap, flexibility

Abendroth, Anja-Kristin. 2020. The Gender Pay Gap in the Platform Economy: Comparing the Importance of Market and Organisational Dynamics on Two German Crowdworking Platforms. Gender a výzkum / Gender and Research 21 (2): 59-84, http://dx.doi.org/10.13060/gav.2020.011.

In times of increased female labour market participation, coordinating a partnership, employment, and family tasks becomes more complex. As a consequence, the demand for employment that can be adapted more flexibly to fit personal needs and different life plans has increased.

In the platform economy, paid work organised via online platforms, often labelled 


\section{NV STATI / ARTICLES}

crowdwork, is a new form of flexible work (Leimeister et al. 2016; Pongratz, Borman 2017; Vallas, Schorr 2020). It offers a large variety of work tasks that do not require a person to be at a specific location (Pongratz, Borman 2017; Wood et al. 2019). The work tasks can instead be done completely digitally using internet-ready devices, such as computers and smartphones, which enable locational work flexibility. Crowdwork has thus also been described as a new form of working from home (Adams, Berg 2017). Moreover, it is the worker who chooses the work tasks and decides when to use the platform to search for and complete tasks. This work situation offers a high level of work autonomy (Wood et al. 2019; Schorr et al. 2020).

Whether crowdwork as a new form of flexible work also translates into smaller gender pay inequalities, however, remains unclear. Crowdwork has the potential to accommodate the increased interest in flexibility among employees, especially women, who still face a more pronounced double burden of work and family responsibilities (e.g., Dechant, Blossfeld 2015; England 2010; Treas, Drobnic 2010). Moreover, in contrast to the flexible workplace arrangements available in conventional establishments, such as telework or flexi-time, in crowdwork the dynamics of gift exchange, where employees work longer hours in return for the 'gift of flexibility', are less likely to come into play (Chung, Van der Lippe 2018). Similarly, flexibility stigmas, where women in particular are perceived to be less productive when they work at home and experience pay penalties for using flexible work arrangements, are also less likely to occur (Lott, Chung 2016; Lott, Abendroth 2020). Nevertheless, the first evidence on work organised through the Amazon Mechanical Turk online platform reveals a gender wage gap of between 10\% and 20\% (Adam 2020; Adam, Berg 2017; Litman et al. 2020). The ILO (2018) report further indicates an average pay gap of between $18 \%$ and $38 \%$, depending on the platform. For the online platform Uber, which mediates taxi rides, Cook et al. (2018) also show a gender pay gap that they explain by men's accumulated experience and the locations in which they drive. However, this form of platform work, often labelled gigwork, involves little locational flexibility and is not the focus of this research.

This study aims to compare gender inequalities in hourly pay on two German crowdworking platforms that mediate work tasks that can be performed anywhere and remotely. Based on a description of such platforms as a hybrid between an organisation and a market (Kirchner 2019), this study investigates whether the market and organisational dynamics that are highlighted as central explanations for the gender pay gap in established forms of paid work also operate on the two German crowdworking platforms and contribute to a gender pay gap among crowdworkers.

Alternative terminologies are online labour (Pongratz, Borman 2017), remote gig work (Wood et al. 2019) and platform mediated remote contracting (Kenney, Zysman 2019). 
First, I ask whether women earn a lower rate of hourly pay from crowdwork and to what extent this difference can be explained by gender inequalities in the overall labour market. With respect to market dynamics, I discuss whether gendered status beliefs, where men are in general perceived to be more competent and productive in the labour market, also lead to a lower demand for female work on crowdworking platforms, which, in line with the devaluation hypothesis of female work, results in lower hourly pay for female crowdworkers (e.g. England 1992; Ridgeway 2001).

Second, I ask whether there are gender-specific time investment patterns among German crowdworkers that can be attributed to the gendered division of labour and whether mothers' investment patterns result in lower hourly pay. With organisational dynamics, I refer to the predominance of the ideal worker norm in work organisations where a high time investment and presence at the regular work site, which align with traditional male life courses, are tied to higher hourly pay (Acker 1990; Williams et al. 2012, 2013; Kelly et al. 2010). Adam (2020), Adam and Berg (2017), and Litman et al. (2020) provided the first evidence that women's greater family responsibilities and related fragmented work patterns explain a large part of the gender pay gap on the Amazon Mechanical Turk crowdworking platform.

Third, based on the typology by Leimeister et al. (2006), this study further compares gender inequalities in hourly pay between two types of platforms that vary in terms of the skill and complexity of the work tasks (Bergvall-Kåreborn, Howcroft 2014; Leimeister et al. 2016): one is a micro-task platform offering work with unstructured data for blogs, shops, and websites, and the other is a marketplace platform with extensive text production and translation. Previous research mainly researched the gender pay gap for a single platform. Conclusions on the importance of the organisational setting for gender pay inequalities among crowdworkers, however, require systematic comparisons between different platforms.

The data used here are from a unique German Crowdworker Survey fielded within the 'Digital Future' collaborative research programme funded by the Ministry of Culture and Science of the state of North Rhine-Westphalia (Germany). Germany is an especially interesting case, as crowdwork is still mainly an additional source of earnings in the country, and women are, on average, more likely to want to increase their working hours in their current employment but often do not have the ability to do so (Dechant, Blossfeld 2015; Leimeister et al. 2016; Stier, Lewin-Epstein 2003; Treas, Drobnic 2010). Estimates of the percentage of crowdworkers within the active labour force thus far vary between $3 \%$ and $14 \%$ for Germany as a whole (Bonin, Rinne 2017; Huws, Joyce 2016; Pesole et al. 2018; Serfling 2018). 


\section{Crowdwork: a hybrid form of work}

Crowdwork has been defined as a 'new form of paid work' in which individuals solve 'specific problems or provide specific services or products in exchange for payment' via online platforms (Eurofound 2015: 2ff). Crowdwork can here be initiated by the requester (crowdsourcer) or the crowdworker (Howcroft, Bergvall-Kåreborn 2019). The limited time horizon of the exchange between crowdworkers and crowdsourcers suggests that the exchange is merely an economic exchange mediated by the platform. Existing research that focuses on the mediating role of the platform, however, shows that this is not the case. The platform is a third actor that establishes the rules and conditions for the exchange, which it defines in its terms and conditions of business (Bergvall-Kåreborn, Howcroft 2014; Kirchner 2019). The platform's rules must be accepted when crowdworkers and crowdsources register on the platform (Bergvall-Kåreborn, Howcroft 2014). Moreover, the platform adopts elements of an employment relationship that are normally covered by regular work organisations, such as taking control of and monitoring work performance (Schorr et al. 2020; Vallas, Schorr 2020). Kirchner (2019) concludes that the rise of the platform economy involves a new hybrid form of work that resembles something between a market and an organisation.

Existing research on established forms of paid work has provided extensive evidence of a gender pay gap and its persistence over time, where women continue to earn, on average, lower hourly pay than men (e.g. England 2010; Misra, Murray-Close 2014). Market and organisational dynamics have here been addressed as major explanations that can also contribute to gender pay gaps among crowdworkers.

With respect to market dynamics, I refer to explanations that highlight a lower demand for female work, especially for high status positions and well-paid work tasks, owing to gender status beliefs. Gender status beliefs here refer to ascribed gendered competence and productivity, where men are in general perceived to be more competent and productive in the labour market, which in turn results in a general devaluation of female work in the labour market (England 1992; Ridgeway, Correll 2004; Risman 2004). Theories on gender as a status characteristic explain that, in hiring and promotion, people tend to categorise others according to gender and that assumed gendered skills and status perceptions consciously or unconsciously shape judgements and behaviour in hiring and promotion decisions, resulting in lower hourly pay for women irrespective of their human capital and investments (Ridgeway, Correll 2004; Risman 2004). Theories of statistical discrimination in the labour market (e.g., Phelps 1972) have further been used to argue that women are perceived to be generally less productive in the labour market due to the gendered division of labour, with women more likely to interrupt work and work part-time due to parenthood. Research on the self-employed suggests that these forms of discrimination can come 
from creditors or consumers (Budig 2006a, b; Lechmann, Schnabel 2012). Existing research has supported this argument in experimental designs and has attributed net gender pay gaps in survey research to discrimination (for a review, see Misra, Murray-Close 2014).

With organisational dynamics, I refer to Ackers' theory on gendered organisations (1990), which points out that structures and processes in organisations are based on traditional male life courses. Existing literature here refers to the 'ideal worker norm', which describes a worker who works long hours, is highly accessible for work, and is physically present at the regular work site (Williams et al. 2012, 2013; Kelly et al. 2010). This norm of an ideal worker aligns with traditional male life courses and clearly deviates from common female life courses that involve more career interruptions, parttime work, and less availability for work because of the gendered division of labour, where women are still mainly responsible for work in the household (Williams et al. 2012, 2013; Kelly et al. 2010). In work organisations dominated by the notion of the ideal worker, workers' heavy time investment and presence at the regular work site are taken as signals of high productivity and therefore lead to better opportunities to earn higher hourly pay. Existing studies have supported this argument by showing the pay and career penalties attached to part-time work and to career interruptions to have children (e.g. Misra, Murray-Close 2014) and the high pay premiums for overtime work (e.g. Cha, Weeden 2014). Moreover, existing research points to a flexibility stigma, where employees express concerns about the possible limitation of their career opportunities if they use flexible workplace arrangements (Konrad, Yang 2012) when the supervisor in general expects a physical presence (Lott, Abendroth 2020), and/or where using a flexible work time or location results in pay penalties, especially for women (Lott, Chung 2016).

In this following section, I discuss whether the described market and organisational dynamics are similar or different on crowdworking platforms and how they can result in a gender gap in hourly pay among crowdworkers.

\section{Market dynamics on crowdworking platforms and gender inequalities in hourly pay}

On crowdworking platforms, workers have to register on the platform to perform a crowdworking task. The formal hiring processes and personnel selection criteria that are common in established forms of paid work often do not exist (Vallas, Schorr 2020). In addition, tasks are often distributed through a time-based competition that follows the principle of 'first come, first served' (Giard et al. 2019; Howcroft, Bergvall-Kåreborn 2019). Adam (2020) and Litman et al. (2020) further suggest that information on the gender of the crowdworker is not visible on the Amazon Mechanical Turk crowdworking platform, which gives gendered status beliefs less 


\section{NV STATI / ARTICLES}

room to determine men's and women's hourly pay. Adam (2020) thus concludes for Amazon Mechanical Turk that direct gender discrimination on crowdworking platforms does not contribute to a gender pay gap in the hourly pay of crowdworkers. Galperin (2019) instead argues that if gender is an available piece of information on the platform, stereotypes can be especially salient, because the exchange is rather short and the information on the job applicant limited. In line with this argument, Galperin (2019) reveals classic patterns of gender segregation in which women are less likely to be hired for male-stereotyped tasks (e.g., software development) and more likely to be hired for female-stereotyped tasks (e.g., writing and translation). However, given that the two platforms studied in this research involve extensive text production and translation (marketplace platform) and work with unstructured data for blogs, shops, and websites (micro-task platform), gender segregation into ascribed maleand female-stereotyped tasks is less likely to occur.

Nevertheless, status differences between male and female crowdworkers can be established in other ways. Existing research here refers to the importance of (marketplace) bargaining power being part of the overall positioning in the labour market (Durward et al. 2016; Schorr et al. 2020; Vallas, Schorr 2020; Wood et al. 2019). In a qualitative study based on two marketplace platforms, Durward et al. (2016) show that the quality signals of crowdworkers, such as advertising, references, evaluations, and the promoting of one's education and skills, matter for the task distribution. More specifically, these quality signals help crowdworkers to achieve critical bargaining power so that they can select the best job offers or even set their own prices, as job offers are often posted to a selected group of crowdworkers (Durward et al. 2016). If quality signals such as references and documented skills are not available, critical bargaining power can be gained by collecting many positive evaluations of the jobs already performed by crowdsourcers and/or the platform (Durward et al. 2016). In the same vein, Schorr et al. (2020), Vallas and Schorr (2020), and Wood et al. (2019) highlight that crowdworkers who are less dependent on the platform can refuse lowpaying tasks and can position themselves more advantageously in the online labour market (Vallas, Schorr 2020). Given that women are disadvantaged in the overall labour market, they may have less bargaining power on crowdworking platforms. Women, especially those with children, have difficulty re-entering the labour market, work in jobs that receive lower pay on average, or earn lower pay when they are self-employed (e.g. Budig 2006a, b; England 2010; Lechmann, Schnabel 2012; Misra, Murray-Close 2014). As a consequence, differences in overall labour market positioning and associated bargaining power between men and women can contribute to gender inequalities in hourly pay from crowdwork. Differences in bargaining power can, for example, become visible in different opportunities to use quality signals to obtain a work task (Durward et al. 2016) or to be picky about selecting tasks (Schorr et al. 
2020; Vallas, Schorr 2020; Wood et al. 2019). The study by Litman et al. (2020) on Amazon Mechanical Turk reveals that women are indeed more likely to select tasks that have lower advertised hourly pay than men.

The importance of (marketplace) bargaining power for hourly pay from crowdwork is, however, likely influenced by the organisational design of the platform. The platform structures which information can be used by crowdsourcers to distribute work tasks to a specific group of crowdworkers, who then compete for the task according to the principle of 'first come, first served'. Moreover, the platform structures what information crowdworkers can provide as quality signals - for example, in short profile descriptions. Algorithmic task distribution then uses information on the demand for specific groups of workers and their evaluations to filter tasks to workers with higher bargaining power (Bergvall-Kåreborn, Howcroft 2014; ILO 2018; Schorr et al. 2020; Vallas, Schorr 2020). This also suggests that people with less bargaining power have less of an opportunity to pick higher-paid tasks because they are filtered away from them. A system of algorithmic task distribution that relies on data that mirror differences in bargaining power between men and women then reinforces a lower demand for female crowdworkers. In line with this, existing research suggests that when algorithms are in play, they are likely to reproduce existing inequality structures in the labour market because the inequality structures are inherent in the data used by algorithms (Barzilay, Ben-David 2015; Folkerts et al. 2019). This pattern leads to the following hypothesis:

H1: Women earn lower hourly pay from crowdwork than men, which can partly be explained by differences in their employment status and positioning in the overall labour market (indicated by their employment, self-employment, and pay in addition to crowdwork).

\section{Organisational dynamics on crowdworking platforms and gender inequalities in hourly pay}

The performance of work tasks on crowdworking platforms clearly deviates from the expectation that a worker be physically present in the workplace, which is part of the ideal worker norm in established forms of work organisations. Work tasks can often be performed irrespective of location, and workers can choose when work tasks are performed (e.g. Adam, Berg 2017; Schorr et al. 2020; Wood et al. 2019). In addition, work on crowdworking platforms is currently seldom performed as full-time work, and crowdworking tasks tend to be short-term (Huws, Joyce 2016; Leimeister et al. 2016; Serfling 2018). However, it is still likely that crowdworking platforms establish a norm in which the ideal worker is one who is highly available for crowdwork on 


\section{NV STATI / ARTICLES}

the platform so that crowdsourcers can get their tasks performed quickly (GomezHerrera et al. 2017). Existing research indicates that platforms tend to use reputation systems in the form of points, levels, or trophies for the number of performed work tasks or tenure on the platform, which can result in the algorithm granted these crowdworkers easier access to work tasks (Gomez-Herrera et al. 2017). Long tenure and heavy time investment on the platform, even when it is not a person's full-time job, can be signals of high availability on the crowdworking platform. The argument is that crowdworkers who invest themselves heavily in the platform with a relatively large number of crowdworking hours, tasks, and long tenure on the platform have easier access to better-paid work tasks, not only because they are more familiar with the processes involved and have gained skills for the crowdworking tasks on the platform (Litman et al. 2020), but also because platform algorithms reward crowdworkers' accessibility for the task and/or pay distribution. Interestingly, when we compare this to established forms of paid work, women and men in Germany currently seem to be more equally accessible for work on platforms, despite the gendered division of labour, because crowdwork is mainly an additional source of earnings and women are more likely to work part time and to be looking to increase their working hours (Huws, Joyce 2016; Pesole et al. 2018; Serfling 2018; Stier, Lewin-Epstein 2003). Men are better positioned in the labour market and thus may be prevented from participating more in crowdworking (Budig, Hodges 2010; England 2010).

Existing research on crowdworking platforms, however, indicates an additional characteristic of the ideal worker norm that exists on platforms and follows traditional male life courses. Adam and Berg (2017) showed that for crowdwork organised via Amazon Mechanical Turk there are pay penalties for more fragmented work patterns, the kind of patterns that motherhood tends to require, where longer task completion leads to lower pay. In line with this finding, Serfling (2018) suggests that the work-family situation matters for which tasks are chosen on the platform. Serfling (2018) shows that in Germany, women are more likely to do short-notice work tasks and tasks that take a rather short time. This finding suggests that mothers earn less hourly pay on crowdworking platforms because they have more fragmented work patterns and are thus able to do fewer tasks per hour. This indicates that the speed of task performance is considered in the algorithmic task distribution or in the evaluations by crowdsourcers. Based on this finding, the following hypothesis is formulated:

H2: Mothers earn lower hourly pay from crowdwork than fathers and childless men and women, which can partly be explained by their slower task performance (fewer tasks per hour) on crowdworking platforms. 


\section{Differences between platform types}

A growing research field has established that work organisations vary in their inequality regimes depending on their history, composition, policies, or cultures (for a review, see Tomaskovic-Devey, Avent-Holt 2019). Given that crowdworking platforms are described as a hybrid between the market and the organisation, it is expected that gender pay gaps on crowdworking platforms differ as well. Leimeister et al. (2016) identified different types of crowdworking platforms based on the tasks performed and observed differences in the prevailing working conditions (Leimeister et al., 2016). This research compared a marketplace and a micro-task platform, which partly displayed the type of segregation commonly observed between professional and non-professional workers in self-employment (Budig 2006a, b) and typologies that distinguish between low and high levels of skill and complexity in the platform's work tasks (Vallas, Schorr 2020). According to Leimeister et al.'s description (2016) of the micro-task platform, the tasks seldom require specific qualifications, are rather short in duration, and involve relatively low pay. Marketplace platforms are instead characterised by more complex tasks that have specific requirements for crowdworkers and can involve higher pay.

On the one hand, I suggest that algorithmic task distribution, which above I argued reinforces a lower demand for female work on the platform, differs between the microtask and marketplace platforms under study. Economic literature has highlighted that algorithmic task distribution is used to reduce the transaction costs on a platform (for a review of the economic literature, see Vallas, Schorr 2020). These transaction costs are especially involved in the distribution of skilled tasks as they are difficult to control. As a consequence, it can be expected that the marketplace platform is more likely to rely on an extensive algorithmic task distribution that reinforces a gender pay gap on this platform. By contrast, for the micro-task platform, it can be expected that the 'first come, first served' principle of task distribution predominates and leaves less room for the devaluation of female work based on algorithmic task distribution.

On the other hand, I expect that more fragmented work patterns, where mothers are slower in their task performance, matter more for task distribution, evaluation, and pay on the marketplace platform. On the marketplace platform tasks are more complex and information on the time required for a task is more likely to be used in evaluations by the platform and/or the crowdsourcer. Fragmented work patterns due to motherhood are assumed to be less important for micro-tasks, which are rather short. This argumentation leads to the following hypothesis:

H3: Gender inequalities in hourly pay are more pronounced on the marketplace platform than on the micro-task platform. 


\section{Data and Methods}

\section{Data collection}

The source of the data used here is the German Crowdworker Survey, which is fielded within the 'Digital Future' collaborative research programme funded by the Ministry of Culture and Science of the German state of North Rhine-Westphalia. (http://dx.doi. org/10.4119/unibi/2936990; method report: Giard et al. 2019). In the first step, 58 German-speaking crowdworking platforms were identified and relevant data were collected (e.g. the number of registered users, types of typical tasks, commercial register details, and existing studies on the platform). In the second step, platforms were chosen based on the following selection criteria: head office in Germany, number of active crowdworkers in Germany, and level of activity (extent of tasks and how current they were and social media contributions and how current they were). This procedure resulted in the selection of 17 platforms. Of those, the most established platform for each platform type was selected. The four chosen platforms were contacted with individual cover letters introducing the intended content and goals of the survey and information on data security and payment for respondents. The questionnaire was programmed using an online survey tool (Unipark), and the request for participation in the survey was offered as a regular task on the platform or was sent to crowdworkers via e-mail from November to December 2018. The survey period was between 3.5 hours (for the micro-task platform) and 12 days (for the marketplace platform, with a request via e-mail). The goal was to collect 200 completed questionnaires for each platform. The average time that respondents needed to complete the questionnaire was 25 minutes, with a range of 5 to 140 minutes. Moreover, it was possible to interrupt the online survey and continue after a break; this option was used by $3 \%$ to $6 \%$ of respondents. This goal was achieved, as 606 completed questionnaires were collected. Of these, 9 were excluded from the data set because the respondents gave an incorrect answer to a control question included in the questionnaire. For this research article, the analyses were based on a sample of crowdworkers on two platform types, a marketplace platform and a micro-task platform, that clearly differed in the complexity of tasks provided in ways that resemble common differences between professional and non-professional tasks in self-employment, but which also clearly vary in other respects, as described below.

\section{Marketplace platform}

Tasks on the marketplace platform involve extensive text production and translations for blogs, shops, or websites, which often require specific skills. Overall, only $20 \%$ of the respondents reported that tasks on the platform require no previous work experience or skills. A large share of crowdworkers on the platform reported that 
skills other than formal qualifications and occupational experience are important (reported by 55\%), but only a small share reported that these skills are the only requirement (26\%). In addition, 31\% reported that a formal educational degree is required (only $4 \%$ reported that a degree is the only requirement), and $34 \%$ reported that experience in their occupation is required (only $3 \%$ reported that this experience is the only requirement) for the tasks they perform on the platform. According to $94 \%$ of the crowdworkers in the sample, the platform and/or the crowdsourcer evaluates work performance. Task distribution involves a time-based competition for work tasks with fixed pay following the principle of 'first come, first served'. However, tasks are mainly distributed to just a select group of crowdworkers registered on the platform based on selection criteria that can be applied by the crowdsourcer. Communication between crowdworker and crowdsourcer is sometimes part of the exchange, and crowdsourcers can even select a specific crowdworker - for example, the one who performed the last task that the crowdsourcer posted on the platform. Most of the crowdworkers on the marketplace platform have a high level of education (58.3\% have a university degree), are self-employed in addition to doing crowdwork, and have relatively long seniority on the platform (around half of them have been there for more than 5 years). More than half of them are female and only $30 \%$ of the respondents are 35 years old or younger (see also the methods report in Giard et al. 2019). Altogether 176 respondents provided valid information on all the measurements for the marketplace platform. Table $A$ in the Appendix presents the descriptive statistics on the present sample of crowdworkers on the marketplace platform.

\section{Micro-task platform}

Tasks offered on the micro-task platform typically involve working with unstructured data such as texts, pictures, or videos - for example, tagging pictures or categorising data. The tasks are rather short and place few skill requirements on crowdworkers. Overall, $58 \%$ of the respondents reported that no previous work experience or skills are required for the tasks on the platform. Relevant skills other than formal qualifications and occupational experience were reported to be important by $16 \%$ of crowdworkers on the micro-task platform (7\% reported that these skills are the only requirement). In addition, $16 \%$ reported that a formal educational degree is required, and $15 \%$ reported that experience in their occupation is required for the tasks they perform on the platform. The task distribution on the platform involves a time-based competition for work tasks with fixed pay assigned according to the principle of 'first come, first served'. Descriptive information further shows that the average hourly pay is lower on the micro-task than the marketplace platform (see Tables A and B in the Appendix). Evaluations seem to be less frequent than 


\section{NV STATI / ARTICLES}

on the marketplace platform. On the micro-task platform, $76 \%$ of respondents reported that evaluation by the platform and/or crowdsourcers is common. Another difference between the platforms is that crowdworkers on the micro-task platform are less qualified. In addition, the share of men and women on the platform is more equal. Moreover, more than half of them are 36 years old or younger, and only a few of them are self-employed and have a long tenure on the platform, in contrast to the crowdworkers on the marketplace platform (see also the methods reported in Giard et al. 2019). In total 178 respondents provided valid information on all the measurements for the micro-task platform. Table B in the Appendix provides descriptive statistics on the present sample of crowdworkers on the marketplace platform.

\section{Measurement}

Log hourly pay: Hourly pay is calculated by dividing the reported average monthly pay for crowdworking by the average number of hours spent monthly on such work. A log transformation of hourly pay is used because the distribution of pay deviates from a normal distribution.

Gender and parenthood: Gender and parenthood status were part of the survey and were used as a categorical variable in the analysis to distinguish between mothers, childless women, fathers, and childless men. Table A in the Appendix displays the descriptive statistics on log hourly pay for mothers, fathers, and childless men and women for the marketplace and micro-task platforms.

Investment in the crowdworking platform: The average total monthly crowdworking hours displays the overall time investments in crowdwork (CW hours). The share of crowdworking hours on the described marketplace or micro-task platform (share of $\mathrm{CW}$ hours on the platform) and the number of months registered on the platform are used to indicate the amount of time invested in the marketplace and micro-task platforms. To measure fragmented work patterns and slower task performance, the number of crowdworking hours per month was divided by the number of work tasks done per month on the platform to give the average number of tasks performed per crowdworking hour.

Labour market involvement and income in addition to work on the platform: Employment status was used as a categorical variable $(0=$ Not regularly employed; 1 $=$ Employed; 2 = Only self-employed). Those who were not regularly employed were involved in childcare, were retired, or did irregular or minor work. Working hours in other employment measured the average monthly working hours in any other major employment the respondent performs besides crowdwork. To measure gross monthly pay, the total gross monthly pay reported was subtracted from the total monthly pay received from crowdwork. Gross monthly pay was top coded by 20,000 Euro per 
month (relevant for two respondents) and then log-transformed as the distribution of pay deviated from a normal distribution.

Skills requirements and age: Information was used on whether the respondents perform tasks with specific knowledge as a requirement. Respondents were asked whether they take work tasks that require as a prerequisite (a) their educational or vocational qualification, (b) the whole of their work experience, (c) other specific knowledge they have acquired, or (d) no specific knowledge. Answers were provided on a five-point scale for these four items combined to assess whether the respondents mostly do qualified work tasks. The answer categories for (d) were reversed so that high values indicated requirements for specific knowledge. The highest level of education, educational field, occupational field, and length of time working in their occupational were only included in sensitivity analyses. Adding these indicators, however, did not change the results. This finding is in line with existing research on the selfemployed (Budig 2006a, b; Lechmann, Schnabel 2012) and a prevailing finding that crowdworkers in Germany are, in general, highly qualified (Leimeister et al. 2016) and that qualifications are balanced between male and female crowdworkers (Litman et al. 2020). An additional sensitivity test further showed that age matters for hourly pay on the platform. Here, those who were older earned lower hourly pay on both platforms. Therefore, age was included as a control variable in the models.

\section{Method}

To investigate the gender pay gap for the marketplace and micro-task platforms and the processes involved, I perform ordinary least squares linear regressions separately for the marketplace platform (Table 1) and the micro-task platform (Table 2). Model 1 shows the overall differences between mothers, fathers, and childless men and women in hourly pay for the marketplace platform and for the micro-task platform, including age and skill indicators as additional control variables. Model 2 investigates the importance of the overall labour market positioning for hourly pay and gender differences in hourly pay on each platform to test hypothesis H1. Model 3 investigates the importance of investment in crowdworking and the importance of this investment, i.e. the amount of tasks performed, for gender inequality in hourly pay on the platform in order to test hypothesis $\mathrm{H} 2$. Model 4 includes both the indicators of overall labour market involvement and crowdworking investment. The comparisons between the models for the marketplace and micro-task platforms serve to test hypothesis $\mathrm{H} 3$. 


\section{NV STATI / ARTICLES}

\section{Results of the multivariate analysis: the gender gap in hourly pay among crowdworkers}

Table 1 and 2 display the results of the regression analysis on hourly pay on the marketplace and micro-task platforms. The results are discussed for each platform separately.

\section{Marketplace platform}

For the marketplace platform, Model 1 in Table 1 reveals that mothers on average earn $35 \%$ less, childless women $40 \%$ less, and childless men $34 \%$ less compared to fathers. Additional analysis shows that differences in hourly pay between mothers and childless men and childless women are not significant. The results further show that older crowdworkers earn lower hourly pay and that those who have accumulated skills for task performance in various ways earn higher hourly pay from crowdwork.

Table 1: The gender pay gap among crowdworkers on the marketplace platform

\begin{tabular}{|c|c|c|c|c|}
\hline & \multicolumn{4}{|c|}{ Marketplace platform } \\
\hline & M1 & M2 & M3 & M4 \\
\hline \multirow{2}{*}{\multicolumn{5}{|c|}{ Gender and Parenthood }} \\
\hline & & & & \\
\hline \multirow{2}{*}{ Mothers } & $-0.346^{*}$ & -0.291 & $-0.289 *$ & -0.266 \\
\hline & $(0.147)$ & $(0.152)$ & $(0.144)$ & $(0.145)$ \\
\hline \multirow[t]{2}{*}{ Childless women } & $-0.401^{*}$ & $-0.346^{*}$ & $-0.327^{*}$ & $-0.307^{\star}$ \\
\hline & $(0.157)$ & $(0.161)$ & $(0.153)$ & $(0.155)$ \\
\hline \multirow[t]{2}{*}{ Childless men } & $-0.337^{*}$ & -0.309 & -0.262 & -0.263 \\
\hline & $(0.168)$ & $(0.169)$ & $(0.164)$ & $(0.163)$ \\
\hline \multicolumn{5}{|l|}{ Other labour market } \\
\hline \multicolumn{5}{|l|}{ involvement and income } \\
\hline \multirow{2}{*}{\multicolumn{5}{|c|}{$\begin{array}{l}\text { Work status (Ref. cat. Not } \\
\text { employed) }\end{array}$}} \\
\hline & & & & \\
\hline \multirow[t]{2}{*}{ Employed } & & 0.065 & & 0.214 \\
\hline & & $(0.196)$ & & $(0.194)$ \\
\hline \multirow[t]{2}{*}{ Self-employed } & & $0.323^{*}$ & & $0.476 * * *$ \\
\hline & & $(0.130)$ & & $(0.140)$ \\
\hline \multirow[t]{2}{*}{ Log gross pay next to $\mathrm{CW}$} & & $0.044^{*}$ & & 0.031 \\
\hline & & $(0.021)$ & & $(0.021)$ \\
\hline \multirow{3}{*}{$\begin{array}{l}\text { Working hours in major } \\
\text { employment next to } \mathrm{CW}\end{array}$} & & -0.004 & & -0.006 \\
\hline & & & & \\
\hline & & $(0.004)$ & & $(0.004)$ \\
\hline \multicolumn{5}{|l|}{ CW investment } \\
\hline Total CW hours & & & -0.006 & $-0.010^{*}$ \\
\hline
\end{tabular}




\begin{tabular}{|c|c|c|c|c|}
\hline & & & $(0.004)$ & $(0.005)$ \\
\hline Share of CW hours on & & & 0.347 & $0.424^{*}$ \\
\hline \multicolumn{5}{|l|}{ platform } \\
\hline & & & $(0.209)$ & $(0.201)$ \\
\hline \multirow[t]{2}{*}{ CW tasks per hour } & & & $0.082^{*}$ & $0.102 * *$ \\
\hline & & & $(0.039)$ & $(0.037)$ \\
\hline \multirow[t]{2}{*}{ Months on platform } & & & $0.004^{*}$ & 0.002 \\
\hline & & & $(0.002)$ & $(0.002)$ \\
\hline \multirow[t]{2}{*}{ Age } & $-0.019 * * *$ & $-0.018 * * *$ & $-0.018 * * *$ & $-0.015^{* *}$ \\
\hline & $(0.005)$ & $(0.005)$ & $(0.005)$ & $(0.005)$ \\
\hline \multirow{4}{*}{$\begin{array}{l}\text { Performance of tasks } \\
\text { where accumulated skills } \\
\text { are required }\end{array}$} & $0.042^{* *}$ & $0.036^{*}$ & $0.042^{* *}$ & $0.039 * *$ \\
\hline & & & & \\
\hline & & & & \\
\hline & $(0.015)$ & $(0.014)$ & $(0.015)$ & $(0.014)$ \\
\hline \multirow[t]{2}{*}{ Constant } & $2.701 * * *$ & $2.375^{\star * *}$ & $2.159 * * *$ & $1.802^{* * *}$ \\
\hline & $(0.298)$ & $(0.312)$ & $(0.352)$ & $(0.363)$ \\
\hline Adj. R2 & 0.102 & 0.167 & 0.163 & 0.239 \\
\hline
\end{tabular}

Source: Crowdworker Survey Data 'Digital Future'.

Note: ${ }^{*} p<0.05,{ }^{* *} p<0.01,{ }^{* *} p<0.001$; Standard errors in parentheses.

Model 2 adds information on employment status and positioning in the overall labour market. The results show that those who are self-employed in addition to their crowdwork earn higher hourly pay than those who are not employed or only employed in minor or irregular employment. This finding suggests that those who are self-employed possess and/or are perceived to possess the most suitable skills for the performance of well-paid tasks on the platform and receive better access to well-paid crowdworking tasks. The same applies to better positioning in the overall labour market indicated by higher hourly pay earned through crowdwork. The change in the coefficients for the gender/parenthood combination from Model 1 to Model 2 shows that considering gender differences in labour market positioning explains part of the hourly pay differences between fathers and mothers (5\%) and between fathers and childless women (5\%) and men (3\%). The descriptive statistics in the Appendix also confirm that the share of crowdworkers who are not employed is smallest for fathers and that fathers also earn the highest gross pay through crowdwork. This finding indicates a pay advantage for them even though fathers are also less likely to be self-employed and more likely to be older. Overall, these results provide some evidence for hypothesis $\mathrm{H} 1$, which argued that women earn lower hourly pay from crowdwork than men, which can partly be explained by differences in their employment status and positioning in the overall labour market (indicated by their employment, self-employment, working hours, and pay from crowdwork). 


\section{NV STATI / ARTICLES}

In Model 3, crowdworking investment is included instead of overall labour market positioning. The results show that some forms of crowdworking investment lead to higher hourly pay on the platform but not all. The platform seems to reward tenure (months on platform) and quick task performance (tasks per hour). Comparing the gender pay gap between Model 1 and Model 3 shows that differences in crowdworking investment explain hourly pay differences between fathers and mothers (5.7\%) and childless women (7.4\%) and men (7.5\%). The pay differences between mothers and fathers and between fathers and childless men are no longer significant when differences in crowdworking investment are considered. This finding can be attributed to differences in seniority on the platform, where fathers report the longest seniority and slightly quicker task performance. However, slower task performance seems not only to be related to parenthood. Childless men and women also report slower task performance. This finding provides only some evidence for hypothesis $\mathrm{H} 2$, which argued that mothers earn lower hourly pay from crowdwork than fathers and childless men and women, which can partly be explained by their slower work performance, as indicated by the performance of fewer tasks per hour on crowdworking platforms.

In Model 4, both information on overall labour market positioning and investment in crowdworking are included. Together the overall labour market positioning and investment in crowdwork explain $8 \%$ of the hourly pay differences between fathers and mothers, $9.4 \%$ of the difference between fathers and childless women, and $7.4 \%$ of that between fathers and childless men. Moreover, the pay differences between mothers and fathers and fathers and childless men are no longer significant. Model 4 further shows that overall labour market positioning and crowdworking investment are interrelated as significance and effect size changes. More specifically, pay in addition to crowdwork and months on the platform are no longer significantly related to hourly pay. Instead, total crowdworking hours now reveal that heavy time investment means less pay and not more. The overall adjusted R2 is 0.239 , which indicates that the indicators of overall labour market positioning and crowdworking investments are important predictors of hourly pay for crowdworkers who perform marketplace tasks. Nevertheless, a large part of the differences in hourly pay remains unexplained. 


\section{Micro-task platform}

Table 2: The gender pay gap among crowdworkers on the micro-task platform

\begin{tabular}{|c|c|c|c|c|}
\hline & \multicolumn{4}{|c|}{ Micro-task platform } \\
\hline & M1 & $\mathrm{M} 2$ & M3 & M4 \\
\hline \multicolumn{5}{|l|}{$\begin{array}{l}\text { Gender and Parenthood (Ref. cat. } \\
\text { Fathers) }\end{array}$} \\
\hline \multirow[t]{2}{*}{ Mothers } & -0.040 & -0.064 & -0.084 & -0.076 \\
\hline & $(0.214)$ & $(0.212)$ & $(0.214)$ & $(0.212)$ \\
\hline \multirow[t]{2}{*}{ Childless women } & -0.242 & -0.309 & -0.234 & -0.249 \\
\hline & $(0.213)$ & $(0.211)$ & $(0.215)$ & $(0.212)$ \\
\hline \multirow[t]{2}{*}{ Childless men } & -0.139 & -0.218 & -0.176 & -0.214 \\
\hline & $(0.207)$ & $(0.207)$ & $(0.207)$ & $(0.206)$ \\
\hline \multicolumn{5}{|l|}{$\begin{array}{l}\text { Other labour market involvement } \\
\text { and income }\end{array}$} \\
\hline \multicolumn{5}{|l|}{ Work status (Ref. cat. Not employed) } \\
\hline \multirow[t]{2}{*}{ Employed } & & 0.387 & & 0.418 \\
\hline & & $(0.226)$ & & $(0.230)$ \\
\hline \multirow[t]{2}{*}{ Self-employed } & & $0.757 * * *$ & & $0.746 * *$ \\
\hline & & $(0.211)$ & & $(0.228)$ \\
\hline \multirow[t]{2}{*}{ Log gross pay next to $\mathrm{CW}$} & & -0.000 & & -0.000 \\
\hline & & $(0.005)$ & & $(0.005)$ \\
\hline \multirow[t]{2}{*}{$\begin{array}{l}\text { Working hours in major employment } \\
\text { next to CW }\end{array}$} & & -0.050 & & -0.052 \\
\hline & & $(0.032)$ & & $(0.031)$ \\
\hline \multicolumn{5}{|l|}{ CW investments } \\
\hline \multirow[t]{2}{*}{ Total CW hours } & & & -0.005 & -0.016 \\
\hline & & & $(0.010)$ & $(0.010)$ \\
\hline \multirow[t]{2}{*}{ Share of CW hours on platform } & & & -0.265 & -0.268 \\
\hline & & & $(0.234)$ & $(0.230)$ \\
\hline \multirow[t]{2}{*}{ CW tasks per hour } & & & $0.029 *$ & 0.021 \\
\hline & & & $(0.012)$ & $(0.012)$ \\
\hline \multirow[t]{2}{*}{ Months on platform } & & & 0.004 & 0.004 \\
\hline & & & $(0.002)$ & $(0.002)$ \\
\hline \multirow[t]{2}{*}{ Age } & -0.005 & -0.010 & -0.010 & $-0.012^{*}$ \\
\hline & $(0.005)$ & $(0.005)$ & $(0.006)$ & $(0.006)$ \\
\hline \multirow[t]{2}{*}{$\begin{array}{l}\text { Performance of tasks where } \\
\text { accumulated skills are required }\end{array}$} & -0.002 & -0.009 & 0.001 & -0.004 \\
\hline & $(0.016)$ & $(0.016)$ & $(0.016)$ & $(0.016)$ \\
\hline \multirow[t]{2}{*}{ Constant } & $1.657^{* * *}$ & $1.871 * * *$ & $1.831 * * *$ & $2.026 * * *$ \\
\hline & $(0.326)$ & $(0.330)$ & $(0.370)$ & $(0.377)$ \\
\hline Adj. R2 & 0.000 & 0.044 & 0.029 & 0.073 \\
\hline
\end{tabular}

Source: Crowdworker Survey Data 'Digital Future'.

Note: ${ }^{*} p<0.05,{ }^{* *} p<0.01,{ }^{* *} p<0.001$; Standard errors in parentheses. 


\section{NV STATI / ARTICLES}

In contrast to the marketplace platform, Model 1 in Table 2 for the micro-task platform reveals no significant differences in hourly pay between fathers, mothers, and childless men and women. Also, age and accumulated skills for the performance of crowdwork do not seem to matter for hourly pay on the micro-task platform in this model (but see Model 4 with a significant effect of age).

Labour market positioning in Model 2 and crowdworking investments in Model 3 are only of modest importance for hourly pay as indicated by the very small adjusted R2. Those who are self-employed earn higher hourly pay (Model 2) as do those who do more tasks per hour (Model 3). Model 4, where overall labour market positioning and crowdworking investment are combined in the analysis, shows that both are highly interrelated. Self-employed crowdworkers earn higher hourly pay in part because they manage to perform tasks especially quickly. As mothers are especially likely not to be employed but they also do more tasks per hour, this situation does not seem to be to their advantage. Overall, the results for the micro-task platform do not support hypothesis $\mathrm{H} 1$ or hypothesis $\mathrm{H} 2$. Rather, the results confirm hypothesis $\mathrm{H} 3$, which argued that gender inequalities in hourly pay are more pronounced on the marketplace platform than the micro-task platform.

\section{Conclusion and discussion}

In the platform economy, crowdwork is a new form of flexible work organised via online platforms that has also been called a new form of working from home (Adams 2020). In accordance with the description of crowdworking platforms as a hybrid between a market and an organisation (Kirchner 2019), this study investigated whether the market and organisational dynamics that are highlighted as central explanations for the persistence of the gender pay gap in established forms of work also result in a gender pay gap in hourly pay among crowdworkers sampled from a marketplace and a micro-task platform.

I conclude that only female crowdworkers from the marketplace platform earn lower hourly pay from crowdwork and that this gender pay gap can indeed partly be explained by gender inequalities in the overall labour market. However, women only earn less than fathers and not less than childless men. The results show that fathers are better positioned in the overall labour market, and therefore, have better opportunities to earn higher hourly pay from crowdwork. They are rarely unemployed or in minor or irregular employment and earn the highest pay outside crowdwork. This finding is in line with existing research that has found that differences in the (marketplace) bargaining power of crowdworkers relate to their overall positioning in the labour market and dependence on income from the platform (Durward et al. 2016; Schorr et al. 2020, Vallas and Schorr 2020; Wood et al. 2019). The argument is that those 
who are better positioned in the overall labour market have easier access to betterpaid work tasks not only because they have gained the skills to perform marketplace work tasks on the platform, but also because overall labour market positioning can be used as a quality signal on the platform (Durward et al. 2016) or allows a crowdworker to be picky about which crowdworking tasks to select (Schorr et al. 2020, Vallas and Schorr 2020; Wood et al. 2019). Algorithmic task distribution that relies on data that mirror differences in bargaining power between men and women then further enforces a lower demand for female crowdworkers as well-paid tasks are filtered away from them (Bergvall-Kåreborn, Howcroft 2014; ILO 2018; Schorr et al. 2020, Vallas and Schorr 2020). If gender pay inequalities among crowdworkers were only driven by the differences in bargaining power that stem from their overall positioning in the labour market we would expect to see similar gender pay gaps on the two platforms studied. For the micro-task platform, however, the results show that overall labour market positioning is only of modest importance for hourly pay and results in no significant pay advantage for fathers. One possible explanation is that marketplace platforms that offer tasks that require high levels of skill and complexity are more likely to rely on algorithmic task distribution to reduce transaction costs, as these tasks are more difficult to monitor and control. Overall, this provides some evidence that there is a lower demand for female work on crowdworking platforms, which is consistent with the devaluation hypothesis of female work that has been used to explain gender pay inequalities in established forms of work (Ridgeway 2001; Ridgeway, Correll 2004). Moreover, it supports the argument that work organised via platforms is a hybrid between a market and an organisation (Kirchner 2019) and that organisational settings vary between platforms and that contributes to different inequality regimes.

The results further suggest that that on these platforms the ideal worker norm clearly deviates from the norm that is established in traditional forms of work (Acker 1990; Williams et al. 2012, 2013; Kelly et al. 2010). Workers do not need to be at a specific work site, and the number of hours they work does not seem to lead to higher hourly pay. Interestingly, heavy time investment in crowdwork results in even lower pay on both platforms, which is a disadvantage for hourly pay on the marketplace platform for mothers and childless women and men. One possible explanation is that those who invest more time in crowdwork have not yet reached the critical bargaining power reported by Durward et al. (2016).

Nevertheless, it can be concluded that other gender-specific time investment patterns among German crowdworkers that can be attributed to the gendered division of labour contribute to a gender pay gap at least on the marketplace platform. Long tenure on the platform and quick task performance result in higher hourly pay, which is to the benefit of fathers on the marketplace platform. This finding is in line with the findings of Adam (2020), Adam and Berg (2017), and Litman et 


\section{NV STATI / ARTICLES}

al. (2020) on the Amazon Mechanical Turk platform, which showed that the more fragmented work patterns of mothers resulted in slower task performance and drove the gender pay gap on the platform. As childless women perform fewer tasks per hour than mothers, and childless men perform even fewer tasks per hour than childless women, this finding further suggests that as well as an individual's family situation there are other factors, such as familiarity with the tasks and accumulated skills, that affect the amount of time required to perform a task. Indeed, the descriptive statistics show that mothers tend to have accumulated better skills for performing crowdworking tasks and have more experience in crowdworking than childless men and women. Interestingly, on the micro-task platform, women with children do more tasks per hour than men. The tasks are probably shorter, so the fragmented work patterns of mothers do not affect task performance speed. In addition, rapid task performance is only of modest importance for hourly pay from micro-tasks and does not benefit mothers' pay, pointing again to different processes for task and pay distribution between the platforms. The results further suggest that motherhood is not taken as a signal of lower work productivity on the platform as there is no pay disadvantage compared to childless women and men. However, an overall pay disadvantage for women remains after differences in overall labour market positioning and crowdworking investment are taken into consideration.

This research has limitations. First, the conclusions drawn are not based on a representative sample of crowdworkers in Germany or on these two platforms. Therefore, the conclusions only apply for this specific sample of crowdworkers. Drawing representative samples based on crowdworkers on which there is no registered data is still a challenge for current research. In addition, the sample size is relatively small, which restricts the number of items possible to include in one model and only makes it possible to depict relatively large associations. A larger sample, especially one with more crowdworking platforms, would allow researchers to systematically test the importance that different setups of crowdworking platforms have for generating gender pay inequalities among crowdworkers. More information on the quality signals and distribution processes used by the platform and on the evaluation criteria used by crowdsourcers and the platform would further allow for more nuanced conclusions on the mechanisms that can contribute to or hamper inequalities in hourly pay among crowdworkers. Finally, this study investigated only two mechanisms for the persistence of the gender pay gap among crowdworkers with a focus on the importance of overall labour market positioning and crowdworking investments.

Nevertheless, this study provides the first insights into the importance of organisational settings for gender pay gaps among crowdworkers. It shows that marketplace platforms and micro-tasks are characterised by different regimes of organisational inequality, as has already been suggested in the case of traditional 
work organisations (Tomaskovic-Devey, Avent-Holt 2019). Not only do men and women who perform marketplace tasks and micro-tasks differ in their overall labour market positioning and crowdworking investment, but overall labour market positioning and crowdworking investment are also of varying importance when it comes to determining the hourly pay of crowdworkers on the two platforms. Overall, these results point to the need to systematically study different crowdworking platforms and the organisational settings involved that contribute to or diminish gender pay inequalities among crowdworkers.

\section{References}

Acker, J. 1990. Hierarchies, Jobs, Bodies: A Theory of Gendered Organizations. Gender \& Society 4 (2): 139-158, https://doi.org/10.1177/089124390004002002.

Adams, A. 2020. The Gender Wage Gap on an Online Labour Market: The Cost of Interruptions.

CEPR Discussion Paper DP14294: 1-34, https://ssrn.com/abstract=3518636.

Adams, A., J. Berg. 2017. When Home Affects Pay. An Analysis of the Gender Pay Gap Among Crowdworkers. SSRN Journal, https://doi.org/10.2139/ssrn.3048711. Retrieved 3/3/2020 (https://plu.mx/ssrn/a/?ssrn_id=3048711).

Barzilay, A., A. Ben-David. 2017. Platform Inequality: Gender in the Gig-Economy. Seton Hall Law Review 47 (2): 393-431, https://doi.org/10.2139/ssrn.2995906.

Bergvall-Kåreborn, B., D. Howcroft. 2014. Amazon Mechanical Turk and the Commodification of Labour. New Technology, Work and Employment 29 (3): 213-223, https://doi.org/10.1111/ntwe.12038.

Bonin, H., U. Rinne. 2017. Omnibusbefragung zur Verbesserung der Datenlage neuer Beschäftigungsformen. Bonn: IZA Institute of Labour Economics. Retrieved 3/3/2020 (https://www.iza.org/de/publications/r/188/report- no-80-omnibusbefragung-zurverbesserung-der-datenlage-neuer-beschaftigungsformen).

Budig, M. J. 2006a. Gender, Self-Employment, and Earnings. Gender \& Society 20 (6): 725-753, https://doi.org/10.1177/0891243206293232.

Budig, M. J. 2006b. Intersections on the Road to Self-Employment: Gender, Family and Occupational Class. Social Forces 84 (4): 2223-2239, https://doi.org/10.1353/ sof.2006.0082.

Chung, H., T. van der Lippe. 2018. Flexible Working, Work-Life Balance, and Gender Equality: Introduction. Social Indicators Research 4 (2): 1-17, https://doi.org/10.1007/ s11205-018-2025-x.

Cook, C., R. Diamond, J. Hall, J. A. List, P. Oyer. 2018. The Gender Earnings Gap in the Gig Economy: Evidence from over a Million Rideshare Drivers. NBER Working Paper 24732, https://web.stanford.edu/ diamondr/UberPayGap.pdf.

Dechant, A., H.-P. Blossfeld. 2015. Changes in the Division of Labor Within Highly Educated German Couples When the First Child Is Born. Zeitschrift für Familienforschung 27 (3): 121-144, https://doi.org/10.3224/zff.v27i3.21279. 


\section{NV STATI/ ARTICLES}

Durward, D., I. Blohm, J. M. Leimeister. 2016. Rags to Riches - How Signaling Behavior Causes a Power Shift in Crowdsourcing Markets. SSRN Journal, https://doi.org/10.2139/ ssrn.3159165. Retrieved 3/3/2020 (https://papers.ssrn.com/sol3/papers.cfm?abstract_ id=3159165).

England, P. 2010. The Gender Revolution: Uneven and Stalled. Gender and Society 24 (2): 149-166, https://doi.org/10.1177/0891243210361475.

England, P. 1992. Comparable Worth. Theories and Evidence. New York: De Gruyter.

Eurofound. 2015. New Forms of Employment. Luxembourg: European Union, https://doi. org/10.2806/937385.

Folkerts, F., V. Schreck, S. Riazy, K. Simbeck. 2019. Analyzing Sentiments of German Job References. Pp. 1-6 in IEEE International Conference on Humanized Computing and Communication (HCC), Laguna Hills, CA. Retrieved 3/3/2020 (https://iug.htwberlin.de/wp-content/uploads/2019/09/AnalyzingSentimentsOfGermanJobReferences_ copyright.pdf).

Galperin, H. 'This Gig is Not for Women': Gender Stereotyping in Online Hiring. 2019. SSRN Journal, http://dx.doi.org/10.2139/ssrn.3501207. Retrieved 3/3/2020 (https://papers.ssrn. com/sol3/papers.cfm?abstract_id=3501207).

Giard N, P. Hemsen, M. Hesse et al. 2019. Technical Report, Interdisziplinäre Befragung von Crowdworkern. Bielefeld: Forschungsschwerpunkt Digitale Zukunft. Retrieved 3/3/2020 (https://pub.uni-bielefeld.de/download/2936990/2936992/TechnicalReport_ Crowdworkerbefragung_FS_DigitaleZukunft.pdf).

Gomez-Herrera, E., M. Bertin, F. Mueller-Langer. 2017. Trade, Competition and Welfare in Global Online Labour Markets. A 'Gig Economy' Case Study. Digital Economy Working Paper, JRC Technical Reports 5. Seville, Spain: European Commission. Retrieved 3/3/2020 (https://ec.europa.eu/jrc/en/publication/eur-scientific-and-technical-research-reports/ trade-competition-and-welfare-global-online-labour-markets-gig-economy-case-study).

Howcroft, D., B. Bergvall-Kåreborn. 2019. A Typology of Crowdwork Platforms. Work, Employment and Society 33 (1): 21-38, https://doi.org/10.1177/0950017018760136. Huws, U., S. Joyce. 2016. Crowd Working Survey. The Size of Germany's 'Gig Economy' Revealed for the First Time. University of Hertfordshire: UNI Europa Global Union; Foundation for European Progressive Studies (FEPS). Retrieved 3/3/2020 (https://www. feps-europe.eu/resources/publications/447:size-of-germany-s-gig-economy-revealed-forthe-first-time.html.)

International Labor Office (ILO). 2018. Digital Labour Platforms and the Future of Work: Towards Decent Work in the Online World. Geneva: ILO. Retrieved 3/3/20 (https://www. ilo.org/wcmsp5/groups/public/---dgreports/---dcomm/---publ/documents/publication/ wcms_645337.pdf).

Kuhn, K. M., A. Maleki. 2017. Micro-entrepreneurs, Dependent Contractors, and Instaserfs. Understanding Online Labor Platform Workforces. Academy of Management Perspectives 31 (3): 183-200, https://doi.org/10.5465/amp.2015.0111.

Kelly, E. L., S. K. Ammons, K. Chermack, P. Moen. 2010. Gendered Challenge, Gendered Response. Confronting the Ideal Worker Norm in a White-Collar Organization. Gender \& Society 24: 281-303, https://doi.org/10.1177/0891243210372073. 
Kenney, M., J. Zysman. 2019. Work and Value Creation in the Platform Economy. Pp. 13-41 in Kovalainen, A., S. Vallas (eds). Work and Labor in the Digital Age. Bingley: Emerald Publishing Limited.

Kirchner, S. 2019. Arbeiten in der Plattformökonomie: Grundlagen und Grenzen von 'Cloudwork' und 'Gigwork'. Kölner Zeitschrift für Soziologie und Sozialpsychologie (71) 1: 3-25, https://doi.org/10.1007/s11577-019-00587-w.

Lechmann, D. S. J., C. Schnabel. 2012. Why Is There a Gender Earnings Gap in Selfemployment? A Decomposition Analysis with German Data. Journal of European Labor Studies 1 (6): 1-25, https://doi.org/10.1186/2193-9012-1-6.

Leimeister, M., D. Durward, S. Zogaj. 2016. Crowdworker in Deutschland. Eine empirische Studie zum Arbeitsumfeld auf externen Crowdsourcing-Plattformen. HBS Working Paper Series 323. Düsseldorf: Hans Böckler Stiftung. Retrieved 3/3/2020 (https://hdl.handle. net/10419/146407).

Litman, L., J. Robinson, Z. Rosen, C. Rosenzweig, J. Waxman, L. M. Bates. 2020. The Persistence of Pay Inequality: The Gender Pay Gap in an Anonymous Online Labor Market, PLOS ONE 15 (2): e0229383, https://doi.org/10.1371/journal.

Lott, Y., H. Chung. 2016. Gender Discrepancies in the Outcomes of Schedule Control on Overtime Hours and Income in Germany. European Sociological Review 32 (6): 752-765, https://doi.org/10.1093/esr/jcw032.

Lott, Y., A.-K. Abendroth. 2020. The Non-Use of Telework in an Ideal Worker Culture: Why Women Perceive More Cultural Barriers. Community, Work \& Family 54 (1): 1-19, https:// http://dx.doi.org/10.1080/13668803.2020.1817726.

Misra, J., M. Murray-Close. 2014. The Gender Wage Gap in the United States and Cross Nationally. Sociology Compass 8 (11): 1281-1295, https://doi.org/10.1111/soc4.12213.

Pesole, A., C. Urzí Brancati, E. Fernández-Macías, F. Biagi, I. González Vázquez. (eds.). 2018. Platform Workers in Europe. Luxembourg: Publications Office of the European Union. https://doi.org/10.2760/742789.

Phelps, E. S. 1972. The Statistical Theory of Racism and Sexism. The American Economic Review 62 (4): 659-661.

Pongratz, H., S. Bormann. 2017. Online-Arbeit auf Internet-Plattformen. Empirische Befunde zum 'Crowdworking'. Deutschland. Arbeits- und Industriesoziologische Studien 10 (2): 158-181.

Ridgeway, C. L., S. J. Correll. 2004. Unpacking the Gender System: A Theoretical Perspective on Gender Beliefs and Social Relations. Gender \& Society 18 (4): 510-531, https://doi.org/10.1177/0891243204265269.

Ridgeway, C. L. 2001. Gender, Status, and Leadership. Social Issues 57 (4): 637-655, https://doi.org/10.1111/0022-4537.00233.

Risman, B. J. 2004. Gender as a Social Structure: Theory Wrestling with Activism. Gender \& Society 18 (4): 429-450, https://doi.org/10.1177/0891243204265349.

Schor, J. B., W. Attwood-Charles, M. Cansoy, I. Ladegaard, R. Wengronowitz. 2020. Dependence and Precarity in the Platform Economy. Theory and Society 49: 833-861, https://doi.org/10.1007/s11186-020-09408-y.

Serfling, O. 2018. Crowdworking Monitor Nr. 1. Für das Verbundprojekt "Crowdworking 


\section{NV STATI / ARTICLES}

Monitor. Hochschule Rhein-Waal: BMAS. Retrieved 3/3/2020 (https://www.bmas.de/ DE/Presse/Meldungen/2018/ausmass-von-plattformarbeit-in-deutschland-hoeher-alserwartet.html).

Stier, H., H. Lewin-Epstein. 2003. Time to Work: A Comparative Analysis of Preferences for Working Hours. Work and Occupations 30 (3): 302-326, https://doi.org/10.1177/073088 8403253897.

Tomaskovic-Devey, D., D. Avent-Holt. 2019. Relational Inequalities: An Organizational Approach. Cambridge, UK: Oxford University Press.

Treas, J., S. Drobnič. 2010. Dividing the Domestic: Women, Men and Household Work in Cross-National Perspective. Stanford, CA: Stanford University Press.

Vallas, S., J. B. Schor. 2020. What Do Platforms Do? Understanding the Gig Economy. Annual Review of Sociology 46: 273-294, https://doi.org/10.1146/annurev-soc-121919054857.

Wood, A. J., M. Graham, V. Lehdonvirta, I. Hjorth. 2019. Good Gig, Bad Gig: Autonomy and Algorithmic Control in the Global Gig Economy. Work, Employment and Society 33: 56-75, https://doi.org/10.1177/0950017018785616.

Williams, C. L., C. Muller, K. Kilanski. 2012. Gendered Organizations in the New Economy. Gender \& Society 26: 549-573, 10.1177/0891243212445466.

Williams, J. C., M. Blair-Loy, J. L. Berdahl. 2013. Cultural Schemas, Social Class, and the Flexibility Stigma. Journal of Social Issues 69 (2): 209-234, https://doi. org/10.1111/josi.12012.

(c) BY-NC Anja-Kristin Abendroth, 2020.

(a) BY-NC Institute of Sociology of the Czech Academy of Sciences, 2020

Anja-Kristin Abendroth is a junior professor for technical and social change at Bielefeld University and part of the interdisciplinary research programme 'Digital Future'. Her research interests include gender inequalities, work-life balance, flexible working, the digital future of work, and organisational inequality regimes. Contact e-mail:

anja.abendroth@uni-bielefeld.de. 


\section{Appendix}

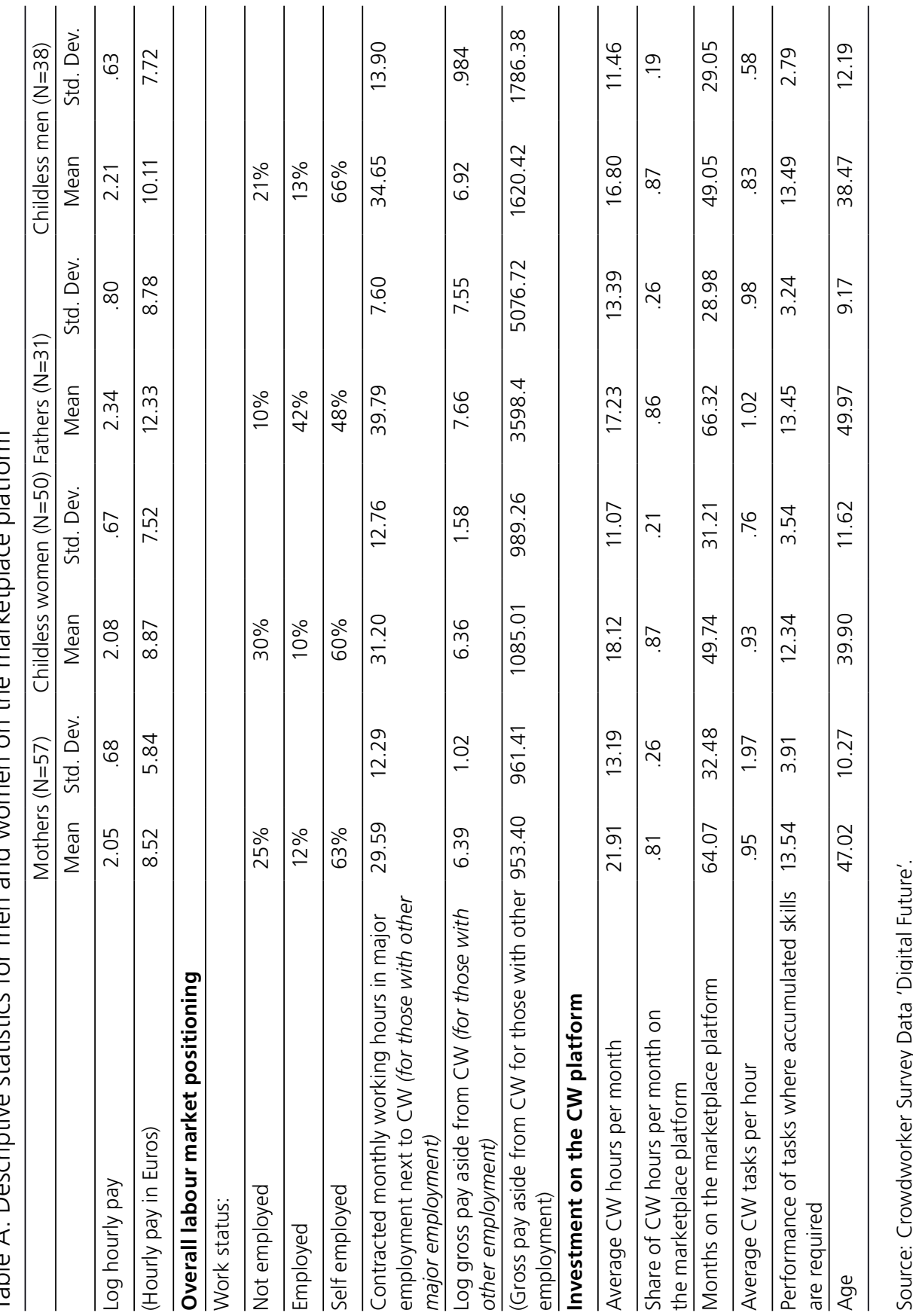




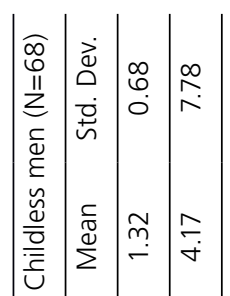

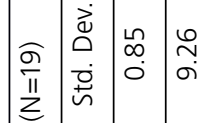

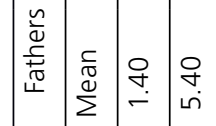

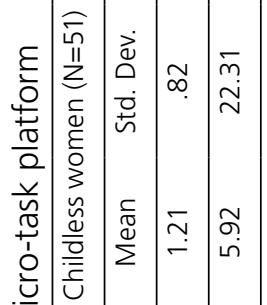

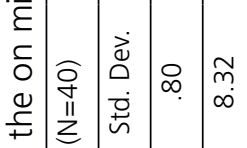

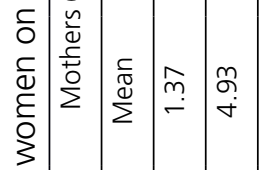

담

ฝ

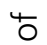

$\stackrel{\tilde{u}}{\underline{n}}$

营

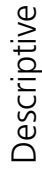

ஸे

带

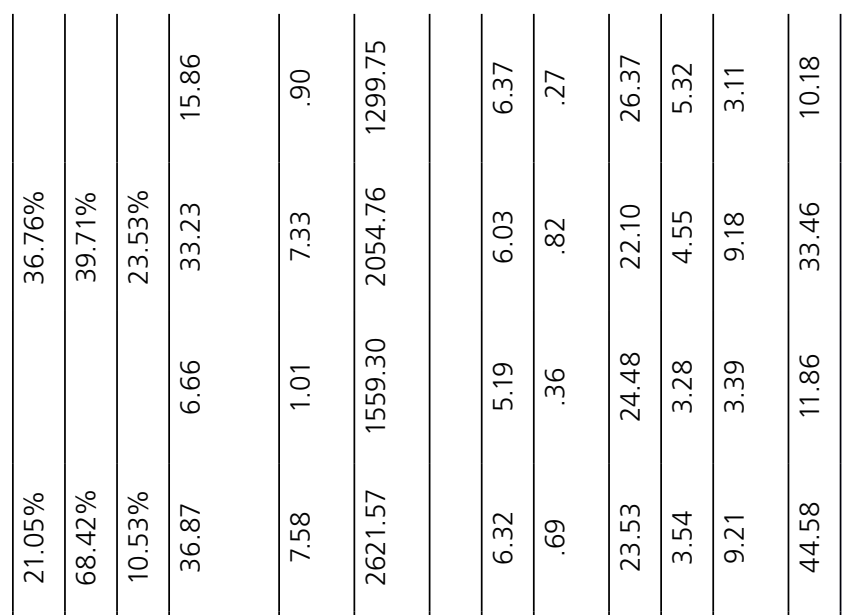

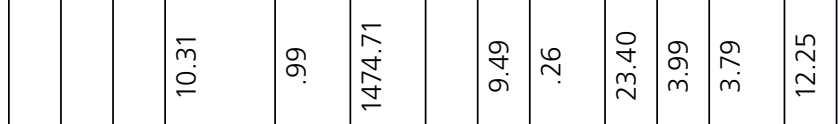

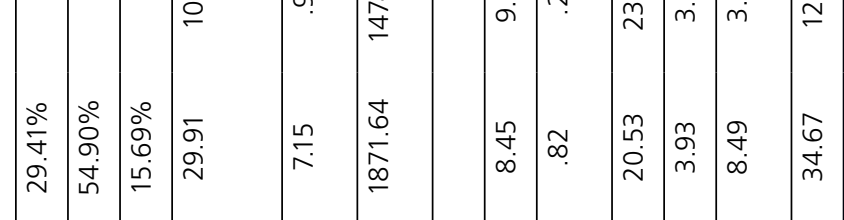

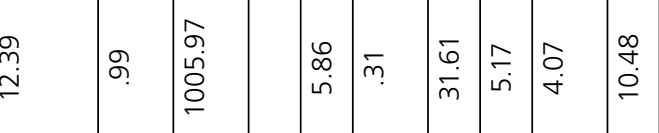

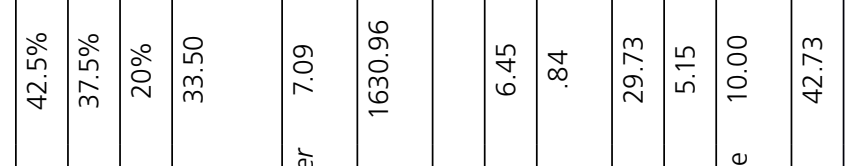

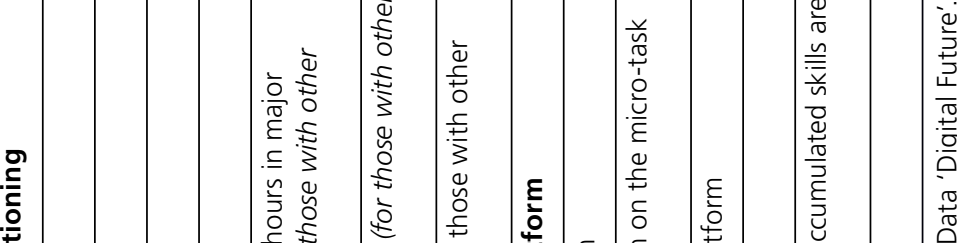

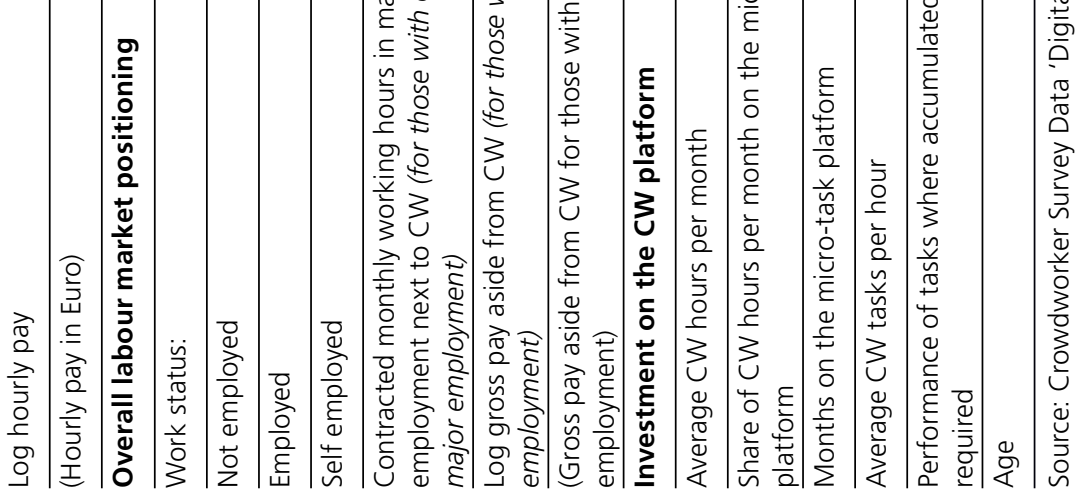

